\title{
Complexity, simplification: funding conservation
}

\author{
CHRIs GreENW OO D
}

Conserving biodiversity is complex and costly. The complexity is illustrated by the failure to make much of a dent in the 2010 biodiversity target of the Convention on Biological Diversity (CBD; Fisher, 2009) and by the negotiations at the 1oth Conference of the Parties to the CBD in Nagoya this October (Adams, 2010; McNeely, 2010). To conserve biodiversity we are bound to pay attention to this complexity-whether of an ecosystem or of a political process such as the CBD_but to raise funds we are obliged to simplify. So how can a fundraiser do justice to the work of his or her colleagues?

As an organization Fauna \& Flora International (FFI) has concerned itself with issues as various as the impact of proposed industrial shrimp farming in the Caribbean Sea, the relative carbon dioxide storage capacities of South-East Asian peat lands and rainforests, and the impact of invasive plant species on native succulents in South Africa. What we conserve, how we do so and why we do it are three of the many tough questions that face conservationists. Yet we have also been capable of dramatic simplicities such as Bats Need Friends. Similarly, how a graphic of a black and white panda has managed to represent field biology, multilateral treaties and tentative estimates of marine carbon dioxide sequestration is a cultural question-a question that reaches back a long way, into iconography and before. But that doesn't stop simplification being uncomfortable, particularly if you care about the biology behind conservation.

We know that the world is messy and unruly and that no matter how programmatic one's approach, unintended consequences abound. For example, an elephant survey in Vietnam eventually led us to work in the international carbon finance markets, partnering with banking institutions (tens of field projects, reams of risk analyses and countless interested parties). When we were scouring Indonesian forests for tigers, elephants and a variety of less charismatic taxa we didn't know that a week later we'd be rebuilding village huts, directing the logistics of an international aid effort and becoming, de facto, a kind of Oxfam, Save the Children and CARE International rolled into one for a year or so-but that's exactly what happened in Aceh after the tsunami of 26 December 2004. We were there, there was a task that needed doing, and so we got on with it.

Despite the world being unpredictable we do still manage to have rules. For example, there must be strategic impact from our work. Conservation is meaningless without thinking about the longer term benefits. We helped in Aceh because that's what any decent organization would do but we also helped because had we not done so, had we not worked to help rebuild the local economy, the attendant biodiversity would have suffered dramatically for years to come.

To my mind one of the most telling dimensions of colleagues working in conservation-what brings us all together, be it donor with charity or conservationist with government-is a shared interest in the long-term consequences of actions taken today. It is the intelligence behind strategy that unites us. Therefore the logic of building local infrastructure, of purchasing and rezoning parcels of land in vital wildlife corridors, of developing communitybased fishing rights, is the logic of conservation. There is no more time to consider conserving biodiversity another way.

Conservationists share a particular instinct. We are all planners. Whether those conservationists are donors or field biologists does not matter. Each of us tends to override the complexity of what we are trying to achieve by seeing in our mind's eye the simplicity of what the world could be like were we to achieve it. Physically, however, the detail of the environment we wish to conserve is a good deal less easy to represent.

This explains why when conservation NGOs focus on individual species, particularly charismatic ones, a large part of the slumbering public may awaken but the more experienced conservationists feel as if the point has been badly missed. Saving pandas just doesn't explain what we do. It doesn't represent the technical dimensions of the biodiversity impact assessment that lies behind the protection order that rezones a landscape that shuts the door to irresponsible mining. Even less does it represent the possibility of responsible mining. It certainly couldn't explain the processes at Nagoya. Imagine raising funds for a meeting of the parties to the CBD.

We do what we have to do to conserve biodiversity. FFI uses instruments where they exist, often innovatively-as lawyers do with laws-and we invent them where they don't exist. Sometimes this is about helping to create an NGO local to a specific conservation problem; sometimes it is about assisting legislation-writing during the transition from one regime to another (both of these are real, recent examples). Fundraising functions in the same way. Ideally we would fully inform every prospective donor everywhere in the world-then they would see the world our way. As it is, we simplify. We use pandas, gorillas and tigers to catch people's attention. We do what we know will work to achieve our funding-it is always ethical, specific and precise but it can rarely duplicate the hard work we have put in to achieve conservation projects and it is not often that we can get the detail across.

It is not so much that as a herd we are not as intelligent as we are individually. It is more that what we see as a herd 
is different to what we see individually. The experienced conservationist knows the world is unruly and full of difficult consequences. The mass of individuals that makes a national population can't consider, collectively, each of the details. As a mass we all know how we respond to tigers. When encountered in the media there is an aesthetic and emotional response, often translated into dollars. When encountered in the wild the herd response to predators is somewhat different.

In short, when one considers the effort to lift biodiversity conservation into the eye-view of the world's politicians, one worries about where the money is coming from. The funding regime for conservation is so very difficult to live with. There isn't enough ( $4 \%$ of grants in the UK went to conservation last year), there aren't enough donors, and the work we do is so technical as to bewilder. That the Conference of the Parties to the CBD meets in Nagoya is a great thing. How do we tell our donors that? It explains why FFI spends rather a lot of time talking to people at senior positions in our society. To them we can explain our case.

But international funds for biodiversity can be like individual bank accounts-variously subjected to pleas for withdrawal. Thus to the oversubscribed the answer is the same. We need to evoke an immediate response to generate an immediate injection of funds, so we look for an immediate subject of appeal. A 3-year grant is always welcome. In year one we celebrate and put our plans in place. In year two we take stock and start to worry. In year three the threat of the whole cycle beginning again looms.
Where is the next grant coming from? Why isn't the fundraising regime easier to live with? Who can we get to fund us in the longer term?

This is, of course, overlooking the detail, the complexity, of the fundraising business. There are plenty of people who understand and who fund us for the long term. These are conservationists. People who share a strategic perspective, who know that as baffling as Conferences to the Parties may be, as worrying as missed targets and failed deadlines and the increasing number of threatened species may be, that to press on and drive conservation forward one needs a mixture of vision and pragmatism. Charismatic species catch the attention and every conservationist knows full well that these species are representative, symbolic, multi-dimensional-strategic in short. So, to all those conservationists who might worry about how we can possibly engage the public, know this: the Cross River gorilla is as good a symbol as any for the processes of the CBD.

Chris Greenwood Fauna \& Flora International, Jupiter House, Station Road, Cambridge, CB1 2JD, UK

E-mail chris.greenwood@fauna-flora.org

\section{References}

Adams, W.M. (2010) Conservation plc. Oryx, 44, 482-484.

FISHER, M. (2009) 2010 and all that-looking forward to biodiversity conservation in 2011 and beyond. Oryx, 43, 449-450.

McNeely, J. (2010) Sharing the benefits of biodiversity: some perspectives from the recent history of conservation. Oryx, 44, $480-481$. 